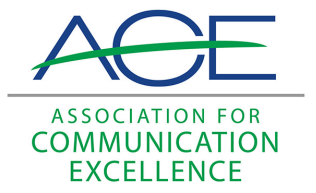

Journal of Applied Communications

\title{
Instructional Crisis Communication for an Industry: Model and Anti-Model Biosecurity Standards for the Prevention and Control of Highly Pathogenic Avian Influenza
}

\author{
Ronisha J. Sheppard \\ Wayne State University \\ Timothy L. Sellnow \\ University of Central Florida \\ Deanna D. Sellnow \\ University of Central Florida
}

See next page for additional authors

Follow this and additional works at: https://newprairiepress.org/jac

Part of the Communication Commons

(c) (i) (3)

This work is licensed under a Creative Commons Attribution-Noncommercial-Share Alike 4.0 License.

\section{Recommended Citation}

Sheppard, Ronisha J.; Sellnow, Timothy L.; Sellnow, Deanna D.; Parrish, Adam J.; and Brand, Jeffrey D. (2020) "Instructional Crisis Communication for an Industry: Model and Anti-Model Biosecurity Standards for the Prevention and Control of Highly Pathogenic Avian Influenza," Journal of Applied Communications: Vol. 104: Iss. 3. https://doi.org/10.4148/1051-0834.2330

This Research is brought to you for free and open access by New Prairie Press. It has been accepted for inclusion in Journal of Applied Communications by an authorized administrator of New Prairie Press. For more information, please contact cads@k-state.edu. 


\title{
Instructional Crisis Communication for an Industry: Model and Anti-Model Biosecurity Standards for the Prevention and Control of Highly Pathogenic Avian Influenza
}

\begin{abstract}
Highly pathogenic avian influenza (HPAl) is a global disease that is increasing in both frequency and intensity in North America. Recent outbreaks of HPAI in lowa, Minnesota, and Indiana resulted in the cumulative loss of millions of birds and over a billion dollars for poultry farmers. This study examined the instructional communication used by state and national responders to promote effective biosecurity intended to limit the spread and impact of HPAI in the three recent outbreaks in the United States. Specifically, the researchers asked, what biosecurity strategies serve as an instructional model for an effective crisis response, and, conversely, what biosecurity strategies serve as an instructional anti-model for an effective crisis response during an HPAl outbreak? Perelman and Olbrechts-Tyteca's (1969) conceptual framework for model and anti-model arguments guided the analysis. Model strategies include maintaining lines of separation protecting healthy birds from exposure, providing instruction that presents biosecurity practices as feasible for workers, having supervisors model the appropriate biosecurity practices, adapting biosecurity plans to fit the needs and resources of individual farms, and realizing the importance of mental health for farmers facing the loss of their animals. Anti-model practices were seen as breaches of the model recommendations. Practical applications include providing instructions on maintaining a line of separation and avoiding common errors, consistently engaging in a biosecurity workable plan prior to outbreaks, providing adequate and timely biosecurity messages as part of a comprehensive and coordinated communication plan uniting farmers, state, and national agencies, and monitoring the mental wellbeing of impacted farmers.
\end{abstract}

\section{Keywords}

Risk Communication, Crisis Communication, Instructional Communication

\section{Cover Page Footnote/Acknowledgements}

This work is/was supported by the USDA National Institute of Food and Agriculture, under award number 2015-69004-23273. The contents are solely the responsibility of the authors and do not necessarily represent the official views of the USDA or NIFA. We have no conflicts of interest to disclose.

\section{Authors}

Ronisha J. Sheppard, Timothy L. Sellnow, Deanna D. Sellnow, Adam J. Parrish, and Jeffrey D. Brand 


\section{Introduction}

Highly pathogenic avian influenza (HPAI) is a recurring global disease increasing in both frequency and intensity in North America. HPAI is particularly worrisome because it can mutate and affect humans. For example, HPAI H5N1 has caused "more than 700 human infections" spread throughout "15 countries in Asia, Africa, the Pacific, Europe and the Near East since November 2003" (Centers for Disease Control and Prevention, n.d.). HPAI H5N5 swept through the Midwest in 2014 and 2015 decimating many poultry farms in Minnesota, Iowa, and Indiana. Although this particular strain of HPAI posed no risk to humans, biosecurity practices within the poultry industry could serve as a first line of defense for avoiding a pandemic if a version of the HPAI H5N1 begins to spread (Food and Agriculture Organization, 2008). Concern over the wellbeing of the United States' poultry industry has resulted in the United States Department of Agriculture prioritizing the development of biosecurity strategies for preventing the spread of HPAI (United States Department of Agriculture, 2016). Clearly, the stakes are high for communicating effectively about biosecurity to all farms threatened by HPAI.

This study seeks to expand our understanding of what and how the agriculture industry communicates about biosecurity standards during actual outbreaks of HPAI. Focusing on outbreaks allows us to assess the role of communication in rapidly disseminating and promoting an effective biosecurity response. The goal of this research is to identify the model (successful) and anti-model (unsuccessful) strategies for maintaining effective biosecurity during such outbreaks. Moreover, this knowledge may contribute to our understanding of appropriate messages for promoting biosecurity practices not only during HPAI outbreaks but also in similar crises affecting the agriculture industry.

We, first, provide a conceptual clarification of model and anti-model arguments and their relevance to biosecurity and instructional communication. Next, we establish our method and 
database. After a discussion of our results, we offer conclusions based on the model and anti-model conceptual framework and practical applications for those charged with providing instructional messages during outbreaks of diseases such as HPAI.

\section{Model and Anti-model Arguments as Crisis Communication}

Discussion of biosecurity in the animal industry can be conceptualized as a contrast between those who closely follow recommendations from government agencies and industry leaders and those who expose themselves to high risk biosecurity factors (United States Department of Agriculture, 2015). Violators of biosecurity standards can compound the risk level for other farmers in their entire region. For example, VanderWaal et al. (2014) assert some animals can be super-spreaders of disease if they are "consistently central in the transmission network" (p. 137). VanderWaal and Ezenwa (2016) further note, due at least in part to such super-spreaders, " $20 \%$ of hosts contribute to around $80 \%$ of the transmission potential of a pathogen" (p. 1606).

Widespread compliance with biosecurity standards is essential because lapses in only a few central network locations could result in exponential spreading of a disease throughout a region. Thus, this study seeks to better comprehend the potential impact of biosecurity messages on an industry through the conceptual framework of model and anti-model arguments established by Perelman and Olbrechts-Tyteca (1969).

Warnick and Kline (1992) explain that Perelman's notion of model and anti-model argument schemes is a means to leverage "the cultural and cognitive predispositions of the audience" (p. 3). They function as a technique that employs "dissociation," a process that separates a unified concept into positive (model) and negative (anti-model) arguments and actions (Schiappa, 1985, p. 73). This process can serve to alter audience's notions of reality, reorient values, and to explain incompatibilities between past and present actions (Warnick \& Kline, 1992). 
Perelman and Olbrechts-Tyteca (1969) note the structure of reality for a given issue can occur through adherence to models and denunciation of anti-models. When speakers propose models or anti-models, they are encouraging audiences to "emulate the one or shun the other" (p. 368). More specifically, model behavior "may serve not only to establish or illustrate a general rule, but also to incite an action implied by it" (p. 362). Conversely, audiences can be "prompted to choose a particular behavior because it is the opposite of the anti-model" (p. 367). From this perspective, effective crisis and risk communication may be illustrated by the contrast between model actions that reduce risk and anti-model actions that increase or even create risk (Sellnow \& Brand, 2001).

Perelman and Olbrechts-Tyteca (1969) claim advocates can engage in strategic communication designed to induce imitation "based on a model that one will be asked to follow" (p. 363). Such strategic communication typically creates incentives for adhering to model behaviors, thereby offering some recognizable degree of prestige. In other words, those whose behavior adheres to the model enjoy more success, respect, or both. In an argument by anti-model, however, "one is trying to get others to be different from someone without it being possible always to infer precise positive behaviors from the distinction" (p. 367). As such, simply stopping a practice or avoiding a practice may be the desired outcome of an anti-model argument. In extreme cases, individuals or organizations engaging in anti-model behaviors can become outcasts or pariahs. As a result, Perelman and Olbrechts-Tytecha characterize anti-model behaviors as "a parody and, sometimes a provocation" (p. 367). Through such refutation, anti-model arguments establish thresholds "below which it is improper to go" (p. 368). Table 1 illustrates the contrasting nature of model and anti-model arguments. 
Table 1

Contrasting Functions of Models and Anti-Models

\begin{tabular}{|c|c|}
\hline Models & Anti-Models \\
\hline Create rules for behavior & Deter discredited behavior \\
\hline Inspired by prestige & Motivated by revulsion \\
\hline $\begin{array}{l}\text { Recommend specific actions for particular } \\
\text { circumstances }\end{array}$ & $\begin{array}{l}\text { Establish what should not be done without } \\
\text { asserting what should be done }\end{array}$ \\
\hline $\begin{array}{l}\text { Close adherence to the model is linked with } \\
\text { reward }\end{array}$ & $\begin{array}{l}\text { Establishes a minimum standard below which } \\
\text { threatens sanctions }\end{array}$ \\
\hline
\end{tabular}

Previous research suggests that model and anti-model arguments have been used to advocate for pro-social behaviors (Diers-Lawson \& Tomaino, 2010), within organizations (Ma, 2019), and in the context of widely distributed disaster warnings (Perry, 2007). Model and antimodel arguments were found to support activities and information by organizations representing a variety of industries during crises including athletic apparel, investment banking, nuclear energy, and hospitality. Sellnow and Brand (2001) explored Nike's use of model argument to respond to and reform practices in athletic shoe manufacturing. Brand (2007) identified model argument techniques used by Merrill Lynch to restore investor confidence after a scandal. Brand (2012) has also identified model and anti-model argumentation as a means to understand the nuclear power industry's responses to the Japanese nuclear power plant meltdown at Fukushima Daiichi. Most recently, Brand and Pohl (in press) have explored model and anti-model argument applied by restaurant industry groups in response to allegations of sexual harassment in the restaurant industry and by celebrity chefs that have been revealed by the activism of the \#MeToo movement. Less attention has been devoted, however, to the potential function model and anti-model arguments may play in providing instructional risk and crisis messages to those facing an imminent risk industry-wide. 


\section{Model and Anti-Model as Instructional Risk and Crisis Communication}

In many circumstances, "human behavior is not learned from the effects of our own actions but by observing others who model certain behaviors and the consequences they experience as a result" (Sellnow, 2018, p. 275). Through this vicarious learning, organizations may ultimately alter their own behavior (Ulmer et al., 2019). As Perelman and Olbrechts-Tyteca (1969) explained, models "incite an action implied by it" (p. 362), while "reference to an anti-model or foil serves to deter people from it” (p. 366). More specifically, Bandura (1986) explained observers essentially choose whether to replicate a behavior based on the observed consequence(s) of that behavior when enacted by others. He went on to contend the survival of humanity depends on the replications of such model behaviors observed in others.

Vicarious learning through model and anti-model observations leads to replication by achieving cognitive, affective, and behavioral learning outcomes (Sellnow et al., 2014). Regarding HPAI, cognitive learning refers to the observer's understanding about how the disease spreads. Affective learning refers to the observer's capacity to realize the potential harm this disease could have on them personally as a member of the industry. Finally, behavioral learning refers to the observer's self-efficacy about taking appropriate actions to protect their organization (model behavior), as well as actions to be avoided (anti-model behavior) to prevent or control the spread of the disease. When these learning outcomes are achieved, instructional risk and crisis communication can serve to "incite" or "inspire" model behaviors and to discourage anti-model behaviors (Perelman \& Olbrechts-Tyteca, 1969, p. 362).

Those who teach others through modeling appropriate behaviors have an "obligation" to oversee their own behavior (Olbrechts-Tyteca, 1969, pp. 364-365). In other words, "a model must keep careful watch on his $[\mathrm{sic}]$ behavior, for the least deviation will be the justification for a 
thousand other deviations, a justification which is often reinforced by use of an a fortiori argument" (p. 365). In other words, those advocating model behaviors who themselves disobey them can ironically become anti-models. Thus, Perelman and Olbrechts-Tytecha reject the adage, "Do as I say; not as I do." Rather, they believe any attempt to justify violations of model behavior as futile.

\section{Research Questions}

Based on our discussion of model and anti-model communication and its relevance to instructional risk and crisis communication, we pose the following research questions:

RQ1: What biosecurity strategies serve as an instructional model for an effective crisis response during an HPAI outbreak?

RQ2: What biosecurity strategies serve as an instructional anti-model for an effective crisis response during an HPAI outbreak?

Developing teachable biosecurity strategies by contrasting model and anti-model behaviors can serve as an instructional reference for the poultry industry. Prevalent threats (such as HPAI) to an industry require a unified response. Implementing model biosecurity behaviors while avoiding anti-model biosecurity failures both aid in preparedness and foster a progressive learning environment within the industry. Through this analysis, we seek to unearth the model and antimodel claims made by those responding to recent HPAI outbreaks, while further explicating the opportunities and constraints of crisis communication at the industry level. 


\section{Case Background}

Avian influenza is a bird flu capable of infecting wild birds (e.g., gulls, ducks, and shorebirds) and domestic poultry (e.g., ducks, geese, chicken, and turkey). Avian influenza can be either low or highly pathogenic depending upon the outbreak. If an outbreak is low pathogenic (LPAI), the symptoms are so miniscule there are no signs of infection in birds. LPAI is a common virus posing no real threat to birds or humans. If an outbreak is highly pathogenic (HPAI), the

consequences are devastating. This form of influenza spreads quickly among both wild birds and domestic poultry.

HPAI had only appeared in the U.S. three times prior to the outbreaks in 2014 and 2015 (1924, 1983, 2004) (United States Geological Survey, n.d.). In 2014 and 2015, however, 15 states were affected by HPAI and over 48 million birds were infected (Greene, 2015). The largest outbreaks occurred in Minnesota and Iowa, and the most recent outbreak occurred in Indiana. Thus, this study focuses on the Minnesota, Iowa, and Indiana outbreaks.

\section{Outbreaks by State}

Minnesota. In March 2015, Minnesota endured the largest outbreak of HPAI H5N2. The outbreak began on March $5^{\text {th }}$ in Pope County and spread quickly throughout 23 counties in the state. Kandiyohi County alone (the largest turkey producing county in the nation) experienced 33 outbreaks (Hughlett, 2015). However, only one of the 704 backyard flocks was affected.

Iowa. Iowa experienced the second largest outbreak. The state's 200 farms were producing around 11 million turkeys per year. As a result of the 2015 outbreak, Iowa lost "approximately thirty million layers and pullets and 1.5 million turkeys due to HPAI" (Decision Innovation Solution, 2015, p. 13). Consequently, the state lost about $\$ 658$ million and 8,444 people lost their jobs. 
Indiana. Outbreaks in Indiana were much smaller than those occurring in Minnesota and Iowa. The first outbreak took place on May 11, 2015 on a backyard mixed poultry farm in Whitley County (Gantz, 2016). Because this outbreak did not affect any commercial farms, it got very little media coverage.

What attracted more concern was an outbreak of a new strand of avian influenza (HPAI A(H7N8)) appearing on a turkey plant in Dubois County on January 15, 2016 (Brown, et al., 2018). The virus spread to nine additional commercial turkey sites within a day. This outbreak was less severe than those in Minnesota and Iowa because all but one site location was infected with a less dangerous subtype (LPAI $\mathrm{A}(\mathrm{H} 7 \mathrm{~N} 8)$ ). In an attempt to help prevent further spread, however, Indiana decided to depopulate all ten sites where avian influenza had been detected, as well as two additional sites identified as dangerous due to their proximity to the infected farms (Brown, et al., 2018). Indiana completed all of this within four days of the initial outbreak.

\section{Method}

\section{Data Collected}

Interviews were conducted with 11 individuals who witnessed and worked alongside those affected by the HPAI crisis. Purposive sampling was implemented through inviting individuals who worked directly with the poultry industry in Indiana (N=3), Iowa (N=3) and Minnesota (N=3). The interviewees were chosen based on their knowledge of the industry and their direct involvement with HPAI outbreaks in their respective states. Interviewees were veterinarians, extension employees, affiliated with the state's board of animal health/state department of agriculture, or a combination of the three. For broader context and a means for verifying transferability of the data, two additional interviews were conducted with individuals involved 
with multiple animal disease outbreaks, including HPAI, while working for the United States Department of Agriculture.

To maintain confirmability, the researchers used a focused interview guide to foster a semistructured conversation between interviewer and interviewee. All interviewees voluntarily completed the interview understanding their identity would remain confidential. Interviewers digressed slightly from the guide when doing so to add depth and breadth to the responses. The interviews were conducted between June 2018 and February 2019. Each interview lasted between 20 and 40 minutes. The interviews were audio recorded and transcribed. Any grammatical idiosyncrasies were intentionally retained in the transcripts to preserve authenticity of the original conversation. The interview transcriptions produced 103 pages of single-spaced content.

\section{Coding Process}

To establish dependability, two trained coders reviewed the transcripts using the definitions of model and anti-model provided by Perelman and Olbrechts-Tytecha (1969). The two coders were experienced in the study of model and anti-model arguments specifically, and risk communication (particularly in the context of biosecurity) generally. The operational definitions used in the code book were:

- Model: behaviors intended to minimize biosecurity risk.

- Anti-Model: behaviors maximizing biosecurity risk.

- Other: topics relevant to biosecurity not directly maximizing or minimizing biosecurity risk.

A single reference was coded from the start of a claim until the speaker changed categories or switched to a different topic. A total of 62 references were identified in the 11 transcripts. Intercoder reliability was calculated using Scott's Pi. The coders achieved an acceptable level of 
reliability of .94 (Krippendorff, 1980). Responses were organized under the headings of producers (people who own or work on a farm) and responders (people who work for local or national agencies).

Finally, to assure the credibility of our analysis, member checks were conducted asking participants whether they believed the researcher interpretations of their statements were accurate (Lindlof \&Taylor, 2011). To do so, the coded statements and discussion were sent to participants inviting them to suggest modifications or corrections where needed. No modifications or corrections were requested.

\section{Results}

Interview data were grouped according to model and anti-model behaviors for producers and for responders. These behaviors are further broken down into subthemes and both examples and direct quotations serve as supporting evidence.

\section{Model Behavior for Producers}

Line of separation. One of the most prevalent model themes mentioned was to create a line of separation. A line of separation establishes a well-defined barrier between healthy animals and potentially infected people and equipment. Interviewee Four explained, the "clean zone ... is inside this line of separation and the dirty zone is outside." Ideally, a model farm would "have a fence around the whole place and have people sign in and sign out, disinfect when they came in and disinfect when they went out" (Interviewee Four). Interviewee Seven argued that strictly maintaining a line of separation should be the top biosecurity priority. Moreover, it is important to "channel your energy there versus like doing you know three thousand percent all the time won't

probably, I don't wanna say tire the people but overwhelm the people because biosecurity is really overwhelming" (Interviewee Seven). 
An emerging subtheme regarding a line of separation emphasized the effective use of the Danish Entry system. Danish entries require all who enter a building housing poultry to remove their shoes on one side of a bench and put on sterile footwear on the other side. This strategy prevents workers from tracking contaminated soil and feces from outside into a closed facility. Interviewee Six explained:

Likewise, for the Danish entry, the more structure you can have for that Danish entry and accommodation for that, I think you know, I don't know if it's been shown or not, but people are more likely to comply with that.

This process also includes washing hands:

You know, people think about washing their hands you know before they eat or something like that, but they don't think about the importance of washing hands you know after you've been working with dirty surfaces and handling birds for some reason. (Interviewee Six) Finally creating structure and consistent regulations were identified as major factors for effectively establishing and monitoring the Danish Entry.

Wild birds must also be monitored to maintain a clean line of separation. Interviewee One shared a method used in Wisconsin to avoid attracting wild birds. On one of the farms, there was a pond with a circumference of 1,500 feet. “The first thing they did was drain the pond, so it wasn't attractive to the wild birds and subsequently put in some sort of a cable system that had low current."

As previously mentioned, distinguishing the areas meant to stay clean from those potentially exposed to disease is essential. Another subtheme emphasized the importance of general farm cleanliness in preserving this distinction. Interviewee One mentioned they could sense the viability of a line of separation simply by looking at a farm from a nearby road: 
Visually it's neat, it's clean, the lawns are mowed, there's no potholes in the driveway, it's a place where you would like to live, it's a place that just speaks care and when you saw those places, both sides of the lawn are mowed, the fences are in good repair, there's no junk, no dead tractors, no piles of garbage.

Interviewee One concluded the upkeep and presentation of the premises suggests the owners care about the health and safety of their birds.

Communication. Effective communication on several levels was also identified as a model theme for producers during an HPAI outbreak. Initially, communicating frequently with veterinarians was identified as an important model behavior. Interviewee Two explained:

Well, for our commercial producers, our main message was to work with their veterinarian, get their premises registered. We have a premises registration here in Indiana for certain livestock species. Poultry are optional. So, we wanted them to opt in.

Interviewee Two identified educating producers as essential during a biosecurity crisis. Another option for speaking with veterinarians is the hotline Indiana set up for producers to call. Interviewee Two emphasized the importance of having producers call this hotline to talk about the symptoms they observed in their birds. Their advice was, "If your birds looked sick and you don't have a veterinarian, call the healthy bird hotline." Respondents indicated such hotlines were available during the outbreaks in all three states.

The importance of internal communication was also emphasized as a subtheme. Interviewee Seven stated, "I think internal communication is very, very important because you might be spreading the virus before you know it because you were just ignorant of that information, you had no idea." Keeping these types of consistent and reliable communication early were described as helpful throughout the crisis. 
Signage was mentioned as an essential form of communication for external audiences. Signage varies depending on county and location but remains a useful tool for maintaining good biosecurity practices. Interviewee 11 shared an example of how a farm in North Central Iowa and another in Central Iowa used signage effectively. They noted this farm had what was, "probably the highest visibility, onsite public presence of messaging to try to keep the Gawker community quote on quote, to a minimum." This method of biosecurity promotion is an effective way to notify those coming on and off the farm of the specific behaviors required.

Planning/Responding. Interviewee Seven emphasized the importance of having a clear, written, and easy to follow plan. They stated, "Have a written plan so that you're not flying at the seat of your pants. It's nice to have a template so that the outbreak has generated a template that USDA uses." Having some sort of written document allows for a point of reference to make planning and responding easier. For example, indemnification (financial reimbursement for euthanized animals) plays a large part in preparing for and responding to animal disease crises. Interviewee Seven explained producers can make use of materials provided by the USDA to help in planning for indemnification, "The other part is a series of audits which is now mandated by USDA. Um if they want the flocks to be indemnified if they need to have a biosecurity plan and they need to have them audited."

A key element in the planning process is establishing a flow of responsibility. Interviewee Seven elaborated on why this makes a difference:

Okay um I think a model facility would be someone who has a very structured chain of command; you know all of the new biosecurity plans need to have sort of a, you know, like a late ring leader like a biosecurity officer that kind of is in charge if something happens. 
In the event of a crisis, Interviewee Seven stressed the importance of having and establishing order. When roles are clearly defined, confusion about what needs to be done and who is in charge is reduced.

Prioritizing Biosecurity. The last model theme emerging for producers is prioritizing biosecurity. In past outbreaks, farms were prepared for some level of biosecurity but not all levels. Interviewee Three explained "a model farm would be some operation that has prioritized biosecurity across all levels of employees from entry level employees, to top manager, CEO and creates a biosecurity culture." Being realistic is also important in biosecurity planning. Interviewee Six said "Biosecurity takes time, umm I mean you know for the work that you're doing you have to allow for time to follow biosecurity or you have to use umm what we call structural biosecurity to make it easier for people to follow biosecurity."

Establishing Strong Social Support Networks. Interviewees also mentioned the importance of establishing strong social support networks to help maintain mental and emotional health when times are tough. Interviewee One explained:

Whether it's biosecurity, mental health security, understanding that you may not see the light at the end of the tunnel this afternoon, there probably is one. Historically, rural people, farm people are not going to go down and get themselves shrunk, they're not going to go talk to a psychologist, their reticent to share their, especially guys, reluctant to share their feelings with anyone and there is a large, here in Wisconsin, large farmer-to-farmer, peerto-peer, grassroots movement that says if you're getting bummed out, you're about ready to go jump off a bridge, call me and I'll be over to talk to you.

As Interviewee One explained, in some of the worst cased scenarios, without a strong social support network, farmers may become suicidal because of the trauma of losing their flock. 
Interviewee One said, poignantly "Suicide's a big deal in these things, [and] it's happening there now."

\section{Model Behavior for Responders}

Communication. As was the case for producers, communication was also a major theme mentioned about responders. The first subtheme was having a customer service orientation. Interviewee Two explained a person from the state who had been on the farm explained the situation directly to producers facing depopulation first-hand. Interviewee Two said the producers "had their [the representative from the state agency] cell phone number and had daily contact with that person. Like I said, it was a high contact customer service perspective. It helped do away with confusion." Personalizing the message through this customer service orientation added to the effectiveness of the biosecurity communication.

Interviewee Seven shared the importance of having a centralized/consistent message:

"So it'll be nice if there was a centralized leadership, a unified message you know whether that's internally or externally to the public that sort of guides either the people on the ground or the people who are reacting to it."

In addition, message accuracy was emphasized as a model behavior. Interviewee Seven explained "you want to deliver the most accurate information rather than confusing or dealing with how fast I can get the information whether it's credible or not right so I think it's a fine balance between the two." Another factor in communication among responders is coordinating among agencies. Interviewee Two shared the importance of coordinating with other states about their testing protocol, "That was one of the challenges and communicating the seriousness of that, you have to trust us, because we are using the best science we have to keep our markets open." 
Encouraging producers to call the hotline was also mentioned as a model behavior for responders. In the previous outbreak, Interviewee Two mentioned, "Getting them to call the healthy bird hotline, the USDA line that they had and getting those calls when they saw something weird going on with their birds and getting those followed up on. That was a challenge."

Planning/Responding. Interviewees stressed the importance of being site specific when preparing for a potential outbreak. Interviewee Three explained:

Well there's three, to identify someone in each location or each site to be a security coordinator, someone who has the oversight and can manage compliance with the protocols. The second is to have that written site specific plan biosecurity and make sure people are aware of it. And the third is to establish protection for the birds, and, depending on the type of building, how they're raised, a series of action steps that they should follow. To further expound on what to do while planning, Interviewee Five emphasized responders should keep the response local. They went on to talk about their own experience and expressed, "You have local experts that do things in peace time that can very much be implemented during war time." Interviewee Five concluded with:

So, when you have people who genuinely care like that, the quality of work that is coming out of there is so high and it works so efficiently you couldn't ask for anything more. I truly think keeping that response as local as possible, this is their industry. They know how to run this industry this is their livelihood. Let them do what they are good at. Interviewees explained maintaining this local and personal focus helps make responders appear both efficient and credible. 
Prioritizing Biosecurity. As on a model farm, prioritizing biosecurity is a model behavior for respondents. To do so, it is vital to make biosecurity accessible. Interviewee Nine shared some valuable points for prioritization:

You know, can you be at heightened biosecurity all the time? Industry is telling us probably not. Um you know we can't be at the operation room level of biosecurity $100 \%$ of the time. It's just not doable. But I would go to the secure poultry or secure pork or secure milk supply plan and that would be the model. Each farm is different, and each model would be different, but the security supply plans provide the basis for the basics of what biosecurity needs to be on the farm. And do it today and not tomorrow.

Compassion. Finally, interviewees stressed the vital importance for responders to exercise compassion with producers who are victims of an outbreak. Interviewee One discussed the reality of the responders having to deal with the aftereffects of an outbreak. He stated, "I think we need to be more realistic with the guy who is impacted, and I often use the term victim." They continued, "these events don't occur because of the fault of some human necessarily." Unfortunately, sometimes good biosecurity does not ensure the farm will not be affected during an outbreak. Interviewee 10 disclosed:

You won't like my answer, but it was a very random deal. I saw farms that would be at what I would consider just super excellent biosecurity and they for some reason or another came down with high path AI and I had other producers who I probably would be crap or very poor and they didn't come down with.

The reality of HPAI is that it is no respecter of persons. Sometimes a farm can follow all the preventative actions and still experience an outbreak. Interviewees stressed that demonstrating compassion for outbreak victims is an important model behavior for responders. 
Each of these themes contributes to establishing and maintaining a model facility. Next, anti-model themes for producers and responders are addressed.

\section{Anti-Model Behaviors for Producers}

Breaches in the line of separation. The line of separation was also emphasized when discussing anti-model examples. Anti-model behaviors in this theme were depicted as breaches in the line of separation. Interviewee Six gave an example of what producers should not do:

Even like garbage pick-up, umm those types of things you know getting back to you know where things may be traveling from one farm to another and you're not even thinking not even thinking about garbage pick-up was at your neighbors you know, your fellow turkey producer's neighbor, coming on to your property. Umm so I guess maybe that might fall in the trap, you know how you control vehicle traffic and personnel traffic on and off the farm,

Interviewee Nine followed up with a concise but compelling instruction by adding, "Don't move poop onto your farm. And don't take poop off of your farm, probably that simple."

Worker shortcuts was another cause of breaches interviewees said should be avoided. Interviewee Six provided an example of someone just coming to do a quick job. They explained, "So I mean you come into the barn, you're going to do something in a rush, no coveralls, no boots, you know nothing like that so what are you going to do?" Interviewees emphasized, although some jobs may be quick and seemingly harmless, following all the biosecurity standards for a line of separation is still essential.

Poor Communication. Much was said about the value of good communication in a model farm. Similarly, poor communication on the farm was identified as anti-model behavior. Interviewee Seven stated: 
Obviously, proximity to the other facility you know if you don't have people who know who's in control, lack of communication you know lack of training. Um what else? I would say lack of communication is probably the most detrimental.

In general terms, interviewees saw communication as essential to keeping all personnel informed for coordinating activities intended to prevent the spread of HPAI.

For producers, informal communication/rumors can also manifest as anti-model behaviors. Interviewee Seven expressed their concern stating:

There's nothing more confusing than having multiple people tell you different things. So actually, I believe with the producer informal network sometimes that creates more confusion um because then you have all these rumor mills circling around and you're just living in the world of uncertainty.

Interviewees emphasized that having open, honest communication from responders to producers can make all the difference in keeping up with and reducing the risks of outbreak on farms.

Poor Organizational Culture. Interviewees noted leadership sets the tone for the culture of an organization. A poor example set by leadership for maintaining biosecurity was identified as anti-model behavior. Interviewee Three described poor leadership as:

The lack of a lack of awareness, maybe make a few more, riskier decisions when it comes to high path and may not have a culture across all. Some of the workers may have it, some of the leadership may not show it or emulate and there's inconsistency in practices so you not only have commitment by the workers to do the things that they're supposed to do, but you also need commitment by the owners, the managers, the companies in that they're willing to commit and provide a culture of commitment to biosecurity. 
Interviewee Three offered a distressing example of anti-model leadership: "So, you have somebody that comes out from a company and kind of just walks into a barn or farm without following any of the biosecurity and your workers see that. It'll be like well okay." The interviewees stressed the need for leaders to set an example for maintaining biosecurity.

Lacking a sense of personal responsibility for ones' neighbors also emerged as an antimodel theme for producers. As Interviewee One explained:

The people who were, as we say in the trade, dirty, infected, almost had lazy, we're on the federal dole attitude and they didn't get it and it was the guys who had the disease, had the virus on their farm who really had a responsibility to their neighbors, not to let it spread from their place. That's where the breakdown came in.

The point here is for producers affected by the outbreak to be personally responsible for stopping the spread of the disease to their neighbors. Once the outbreak hits their farm, Interviewees insisted farmers should do their best to contain it and avoid further spread.

\section{Anti-Model Behavior for Responders.}

Breaches. A surprising source of biosecurity breaches came from journalists. Interviewee Two shared an alarming description of such breaches:

If you look in the $\mathrm{Ag}$ media, there was some criticism. Some of the reporters snuck onto sites that were supposed to be secured and locked down. That presents a threat for carrying the virus off and on. That became a role of the site manager to make sure that wasn't happening, because that looks really bad on the government agencies. It also is bad for the industry because it doesn't lend any credibility to us being the biosecurity experts and making sure things remain contained. 
Interviewees stressed biosecurity applies to anyone entering a farm. This includes owners, workers, and reporters.

Poor Communication. Projecting an image of governmental incompetence was another example of an anti-model response. Interviewee Two mentioned some governmental responders sometimes lacked credibility: "There is a lot of waste and a lot of people standing around and things not working. No one knows who is in charge." This lack of efficiency created a negative impression to farmers that some responders were not aware of their role and how to be of service. This failure suggests, as government officials come onto farms to offer advice, they should be aware of their charge and what information they can and should share.

Another form of poor communication was having to learn about the crisis from outside sources. Interviewee Seven told us, "I had producers and veterinarians who actually found out about the four southeastern outbreaks through Facebook and they were kind of upset about that which I can completely understanding." Interviewee Seven continued, "I think that's what a lot of the producers said you know sometimes they'll get information about the outbreak from outside sources before they actually knew what's happening in their own company." It is important to communicate with those most closely affected by a crisis before the news hits public media outlets.

\section{Discussion}

One of the most interesting observations from this study is how interviewees had considerably more to say about model biosecurity behaviors than they did about anti-model behaviors. Most interviewees stressed known strategies, such as maintaining a clean line of separation, as a blueprint for success rather than identifying actions to avoid. This tendency suggests information is available, such as applying a Dutch entrance or preventing visitors from interacting with livestock, for maintaining biosecurity. The challenge is getting all relevant parties 
to fully engage in consistent biosecurity. Many of the anti-model observations were instances where individuals were aware of proper biosecurity protocols but chose not to enact them.

Breaches in the most critical element of biosecurity, the line of separation, were described as stemming from poor choices and bad examples more than from a lack of proper instruction. Interviewees described farm workers as taking "shortcuts" when reentering the clean side of the line after completing simple tasks on the contaminated side. These shortcuts allowed workers to avoid the cumbersome entry process, but simultaneously raised the risk of contamination. Other than saving time, these breaches may be inspired by a poor example being set by facility owners, managers, or members of the agriculture media. Interviewees characterized such breaches as a poor organizational culture. When an authority figure is observed by farm workers failing to follow biosecurity protocols, this example can lead to what Perelman and Olbrechts-Tytecha (1969) describe as "the justification for a thousand other deviations" (p. 365). In other words, such violations can have a counter-instructive impact where the lessons of biosecurity are dismissed as inconsequential. Thus, the model and anti-model framework provides a clear disincentive for those in leadership or instructor roles to consider violating the lessons they ask their audience to emulate.

As a counter to the impactful violations described above, interviewees stressed that prioritizing biosecurity could inspire model behavior. They caution, however, such prioritization must be realistic. Interviewees explained teaching and practicing biosecurity take time. Such time is needed in both benign and crisis circumstances. Waiting to teach and enforce model biosecurity practices is not feasible in the limited time available at the start of an outbreak. Furthermore, the strategies demanded for biosecurity should be feasible for employees. As interviewees explained, the model behaviors must be easy to follow. Strategies that are difficult or beyond the grasp of a farm worker cannot serve effectively as model behaviors. Thus, this study suggests, for modeling 
to occur, the audience must perceive a high degree attainability or self-efficacy for the suggested actions.

As affirmed by the interviewees, planning is essential for reaching the status of a model facility. Planning should establish clear expectations for essential model behaviors and identify those who will be responsible for training and supervising workers. In addition, plans should account for crisis circumstances with a clearly identified flow of responsibility for decision making. Interviewees also offered suggestions to responders at the state and national levels. Model planning for respondents included enough flexibility to account for differences among farms of varying size and structure. A commonality for both producers and responders was the need to clearly identify and empower the individuals who lead the crisis response at each facility. Thus, on a planning or pre-crisis level, designating and empowering those tasked with promoting biosecurity are essential aspects of model behavior.

Interviewees identified effective instructional communication as essential for establishing model biosecurity protocols. In addition to planning for and modeling effective biosecurity strategies, interviewees said producers need to share biosecurity messages regularly and consistently with members of their organizations. By doing so, producers can counter the two antimodel behaviors noted by respondents: lack of communication and prevalence of rumors. Interviewees explained a lack of communication created frustration for workers and contributed to an unabated flow of rumors and inaccurate information.

Model communication for responders was further characterized by the interviewees as highly personalized. Model responders established interpersonal relationships with personnel on the farms they served and made themselves highly accessible. In general, responders were encouraged to maintain an attitude of customer service where they prioritized learning about the 
audience they served and providing a high level of accountability. This finding suggests instructional communication, from a model and anti-model perspective, functions well when such relationships are valued.

Conversely, communication failures or anti-model behaviors occur when information is not given out in a timely manner. Interviewees reported some producers and even responders had to find out about an outbreak via Facebook and other social networking sites. This lack of communication blindsided responders and producers in locations that could potentially be affected by the outbreak. Therefore, when an outbreak occurs, rapidly communicating to all parties what is known as well as what is not yet known is essential. A positive resource for sharing this information with producers were the hotlines made available in each of the outbreaks.

Realizing the importance of mental health and the potential for suicide among farmers who have lost their flocks due to depopulation was seen as essential by several interviewees. Interviewees explained many farmers see their livestock and their farm as central to their identity. Greene (2015) noted up to 18 months may be required for producers to reestablish their income after there is depopulated. If the farm faces a crisis such as depopulation, the financial loss and ensuing mental effects on farmers can be fatal. Mental health is not typically recognized as a practice of biosecurity, however, the preservation of producers' and farm workers' well-being must be addressed as part of the overall crisis response.

A sobering reality shared by one interviewee was the vulnerability of farms with or without biosecurity. Regardless of the practices put into place, there is still a risk of outbreak. Taking precautions does not necessarily negate the possibilities of harm. However, the majority of the interviewees concur that the risk of diseases such as HPAI is much lower when biosecurity is practiced. 


\section{Practical Applications from a Model and Anti-Model Perspective}

Model biosecurity in response to HPAI focuses predominantly on four areas: a clear line of separation, a workable plan, effective communication, and a comprehensive crisis response.

A clear line of separation is the model for effective biosecurity. If animals can avoid contact with the virus, they cannot be infected. Tangible strategies such as a Dutch entrance and strict limits on visitors to the farm are model behaviors. Maintaining this line of separation, however, also depends on limiting anti-model behaviors in the form of breaches caused by workers taking shortcuts and authority figures failing to comply with the biosecurity protocol.

As with any potential crisis, planning is a model behavior. Plans for addressing biosecurity risks such as HPAI should include ongoing instruction rather than waiting to emphasize biosecurity once an outbreak occurs. Model plans must, to the greatest extent possible, be designed to make the biosecurity practices easy for workers to understand and enact.

Instructional communication is a valuable approach for establishing model and anti-model practices. Model behaviors should be articulated clearly and consistently before, during, and after crises. Framing instructional communication messages as model and anti-model arguments empowers audiences and fills a void that might otherwise be replete with rumors and inconsistent messages. Instructional communication research has established that risk and crisis messages need to incorporate components including internalization of message, action, explanation, and selfefficacy (Sellnow, Lane, Sellnow, \& Littlefield, 2017). Model and anti-model arguments as instructional messages are capable of not only recommending positive and negative actions and behaviors; they can also alter audience perceptions of reality, and advocate value orientations such as leadership and responsibility. 
Finally, responding to HPAI and similar crises should include consideration of the emotional toll on those whose lives are impacted. The trauma of losing one's livelihood and personal identity can be life-threatening. These model responses must also be empathetic and comprehensive.

\section{Limitations and Future Research}

This study is limited to the most recent three outbreaks of HPAI. None of these outbreaks included instances of animal to human infection. If human infections occur on U.S. farms in the future, additional strategies will likely be needed. Similar research focusing on other zoonotic diseases such as Anthrax, Listeriosis, and Lyme disease could add further insight. Future research might also move beyond interviews to simulations where the effectiveness of specific model and anti-model messages might be tested.

\section{Conclusion}

Although biosecurity practices are well known and vigorously promoted by agencies such as the United States Department of Agriculture, the interviewees participating in this project warn breaches of these practices are dishearteningly commonplace. These biosecurity failures, combined with an alarming increase in the global spread of animal diseases, including zoonotic varieties, create a sense of urgency for enhancing animal biosecurity (United Nations, 2020). This study provides reassurance that effective crisis communication can contribute to impactful instruction in biosecurity. Thus, effort devoted to studying the function and form of effective risk and crisis instructional communication for biosecurity is time and energy well spent. Dedication to developing and implementing effective instructional communication strategies for biosecurity will likely make the agriculture industry better prepared to manage the looming plant and animal disease challenges it will undoubtedly face. 


\section{References}

Bandura, A. (1986). Social foundations of thought and action: A social cognitive theory. Prentice-Hall.

Brand, J. D. (2007). Restoring investor confidence via model and antimodel advocacy by Merrill Lynch. In J. L. Courtright and P. M. Smudde (Eds.), Power and Public Relations (pp. 107-123). Hampton Press.

Brand, J. \& Pohl, G. (in press). Model/Anti-Model advocacy responses to hospitality industry sexual harassment. In M. Khosrow-Pour (Ed). Encyclopedia of Organizational Knowledge, Administration, and Technology. IGI Global.

Brand, J. (2012). Incidental crisis management: Strategies and tactics for success. In C.

Zongchao, and C. Spaulding, (Eds). Using theory for strategic practice through global engagement and conflict research. (34-43). Miami: 15th International Public Relations Research Conference Proceedings. https://instituteforpr.org//wp-content/uploads/15th$\underline{\text { IPRRC-Proceedings1.pdf }}$

Brown, J. A., Patel, R., Maitlen, L., Oeding, D., Gordon, K., Clayton, J.L., Richards, S., Potones, P., Brewer, J., Blosser, S., \& Duwve, J. (2018). Public health response to an avian influenza A(H7N8) virus outbreak in commercial turkey flocks- Indiana, 2016. Weekly 67 (48), 1339-1341.

Centers for Disease Control and Prevention. (n.d.). Highly Pathogenic Asian Avian Influenza A(H5N1) in people. https://www.cdc.gov/flu/avianflu/h5n1-people.htm.

Decision Innovation Solutions. (2015). Economic impact of highly pathogenic avian influenza (HPAI) on poultry in Iowa. http://www.decision- 
innovation.com/webres/File/docs/Economic-Impact-of-Avian-nfluenza-on-Poultry-inIowa.pdf

Diers-Lawson, A., \& Tomaino, K. (2010). Comparing Strawberries and Quandongs: A CrossNational Analysis of Crisis Response Strategies.

Food and Agriculture Organization of the United Nations. (2008). Biosecurity for Highly Pathogenic Avian Influenza: Issues and options. file:///C:/Users/ti382580/OneDrive\%20\%20University\%20of\%20Central\%20Florida/Desktop/FAO\%20Report\%20on\%20HPAI. pdf

Gantz, A. (2016, January, 20). Indiana first hit with HPAI in May 2015. WATTAgNet.com. https://www.wattagnet.com/articles/25637-tbt-indiana-first-hit-with-hpai-in-may--

Greene, J.L. (2015). Update on the highly-pathogenic avian influenza outbreak of 2014-2015. Congressional Research Service. https://fas.org/sgp/crs/misc/R44114.pdf

Hughlett, M. (2015 May 26). Minnesota county hit hard by ripple effects of state's bird flu epidemic. http://www.startribune.com/kandiyohi-county-hit-hard-by-ripple-effects-ofbird-flu-in-minnesota/304946811/

Indiana State Board of Animal Health. (n.d.). Indiana poultry production data. https://www.in.gov/boah/2715.htm

Krippendorff, K. (1980). Content analysis: An introduction to its methodology. Sage Lindlof, T. R., \& Taylor, B. C. (2011). Qualitative communication research methods (3rd ed.). Sage.

Ma, L. (2019). I am one of them: Examining crisis communication from an intergroup communication approach. Journal of Contingencies and Crisis Management, 27(1), 5060. 
Perelman, C., \& Olbrechts-Tyteca, L. (1969). The new rhetoric: A treatise on argumentation (J. Wilkinson \& P. Weaver, Trans.). University of Notre Dame Press.

Perry, S. D. (2007). Tsunami Warning Dissemination in Mauritius, Journal of Applied Communication Research, 35:4, 399-417, DOI: 10.1080/00909880701611060

Schiappa, E. (1985). Dissociation in the arguments of rhetorical theory. Journal of the American Forensic Association, 22, 72-82. https://doi.org/10.1080/00028533.1985.11951304

Sellnow, D. D. (2018). The rhetorical power of popular culture: considering mediated texts. Sage.

Sellnow, D. D., Lane, D., Littlefield, R. S., Sellnow, T. L., Wilson, B., Beauchamp, K., \& Venette, S. (2015). A receiver-based approach to effective instructional crisis communication. Journal of Contingencies and Crisis Management, 23(3), 149-158. doi: $10.1111 / 1468-5973.12066$

Sellnow, D. D., Lane, D. R., Sellnow, T. L., \& Littlefield, R. S. (2017). The IDEA model as a best practice for effective instructional risk and crisis communication. Communication Studies, 68(5), 552-567.

Sellnow, T. L., \& Brand, J. D. (2001). Establishing the Structure of Reality for an Industry: Model and Anti-Model Arguments as Advocacy in Nike's Crisis Communication. Journal of Applied Communication Research, 29(3), 278. https://doi.org/10.1080/00909880128109

Ulmer, R. R., Sellnow, T. L., \& Seeger, M. W. (2019). Effective Crisis Communication: Moving from Crisis to Opportunity. Sage. 
United Nations. (2020, July 6). New UN report outlines ways to curb growing spread of animalto-human diseases. UN News. https://news.un.org/en/story/2020/07/1067711

United States Department of Agriculture. (2015). Biosecurity Factors and the Introduction and Spread of HPAI: Findings from Epidemiological Studies.

https://www.aphis.usda.gov/animal_health/downloads/animal_diseases/ai/hpaibiosecurity-factors-introduction-and-spread.pdf

United States Department of Agriculture. (2016). Highly pathogenic avian influenza standard operating procedures: 9. Biosecurity. https://www.aphis.usda.gov/animal_health/emergency_management/downloads/sop/sop hpai_biosecurity.pdf

United States Geological Survey. (n.d.). What is the difference between low pathogenic and highly pathogenic avian influenza? USGS Science for a changing world. https://www.usgs.gov/faqs/what-difference-between-low-pathogenic-and-highlypathogenic-avian-influenza?qt-news_science_products=0\#qt-news_science_products

VanderWaal, K. L., Atwill, E. R., Isbell, L. A., \& McCowan, B. (2014). Quantifying microbe transmission networks for wild and domestic ungulates in Kenya. Biological Conservation, 169, 136-146.

VanderWaal, K. L., \& Ezenwa, V. O. (2016). Heterogeneity in pathogen transmission: mechanisms and methodology. Functional Ecology, 30(10), 1606-1622.

Warnick, B. \& Kline, S. (1992). The New Rhetoric's argument schemes: A rhetorical view of practical reasoning. Argumentation and Advocacy, 29, 1-15. https://doi.org/10.1080/00028533.1992.11951551 
